\title{
APPLYING FEMINIST PRINCIPLES TO PROGRAM MONITORING, EVALUATION, ACCOUNTABILITY AND LEARNING
}

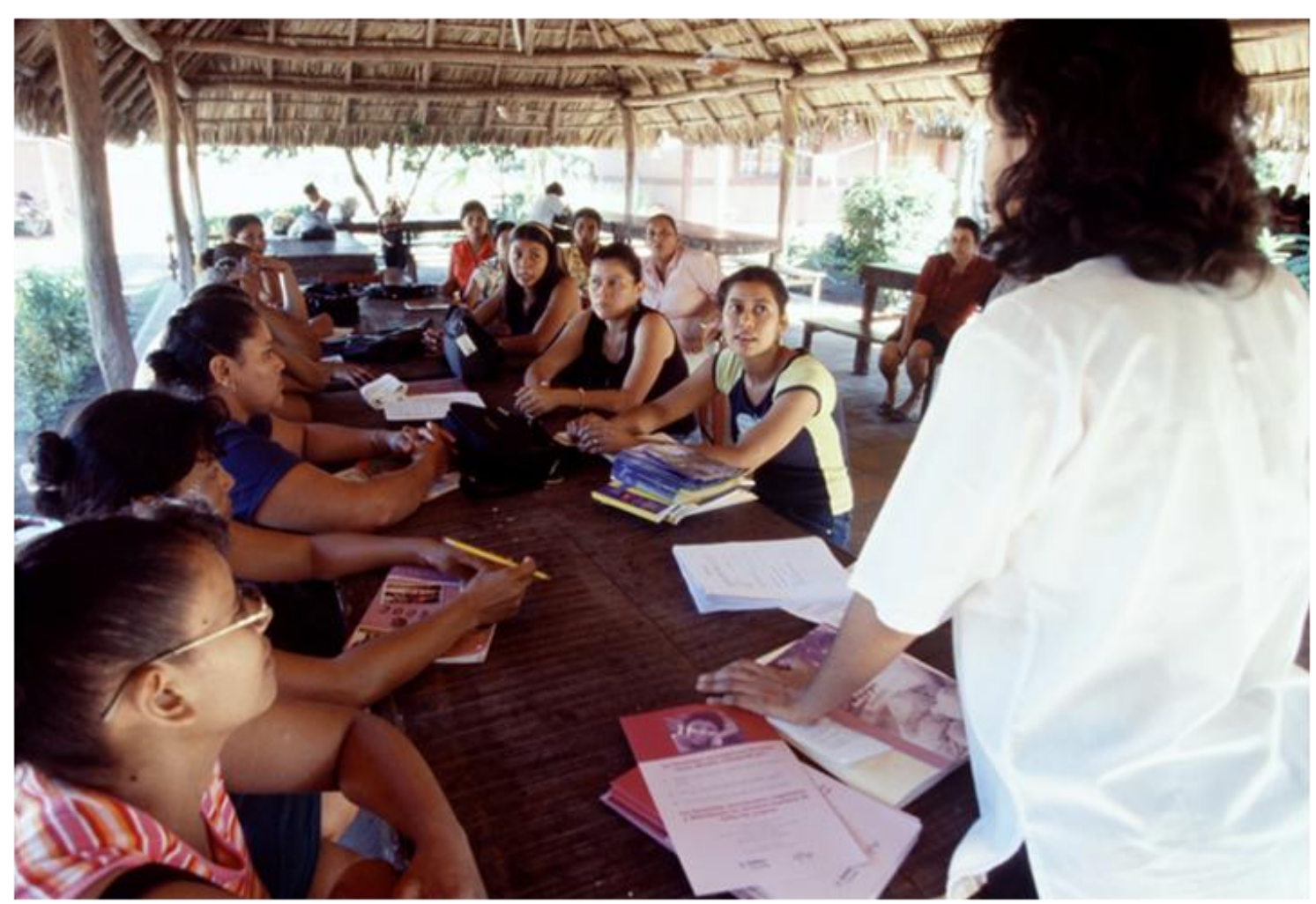

Photo: Pablo Tosca/Oxfam

\section{SHAWNA WAKEFIELD, DANIELA KOERPPEN}

Oxfam is committed to mainstreaming women's rights and to transforming unequal gender and power relations. For its programmes, this means that it needs to track its contributions to these changes. This paper aims to share reflections on how to apply feminist principles to monitoring, evaluation, accountability and learning (MEAL) practice. It includes case studies of Oxfam's experience of applying these principles to its programmes. 


\section{CONTENTS}

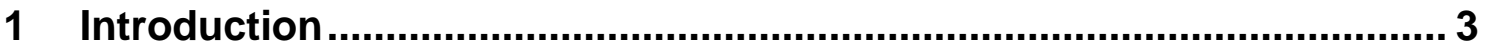

2 What this paper is - and is not ........................................................... 3

3 The complex nature of transformational change .................................... 4

4 Feminist principles applied to Oxfam MEAL ....................................... 6

1 The role of the evaluator and participatory approaches ................................ 6

2 Measurement for non-linear and complex change ....................................... 7

\section{Applying feminist MEAL principles: examples from Oxfam and partner}

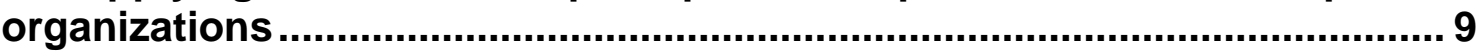

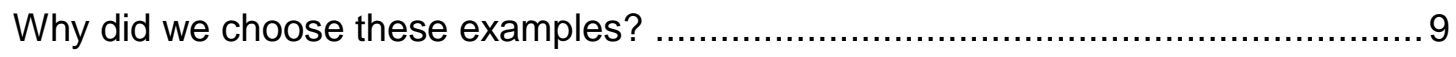

1 AMAL: Supporting women's transformative leadership in changing times in the Middle East and North Africa by Oxfam Intermón ................................................. 10

2 Bringing feminist principles to the assessment of organizational capacity for gender justice: Oxfam Canada's Engendering Change program .......................... 13

3 Oxfam Novib's implementation of 'Most Significant Change' in the context of Gender Mainstreaming and Leadership Trajectory (GMLT) ................................ 15

6 Next steps and recommendations..................................................... 17

Feminist principles and log-frame approaches .......................................... 17

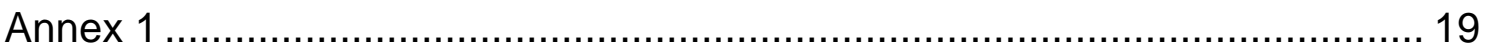

Oxfam Gender and Feminist Monitoring, Evaluation, Accountability and Learning event.....

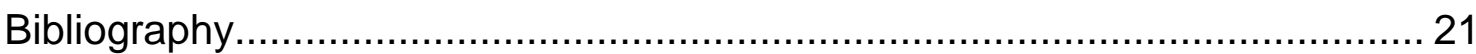

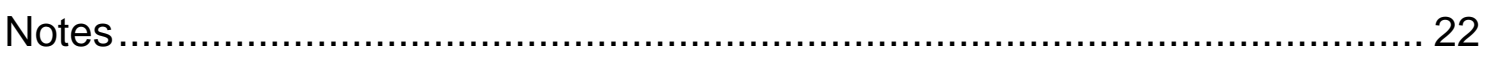

\section{ACKNOWLEDGEMENTS}

This paper has benefited enormously from contributions from case study authors Laura Haylock, Samia Khayyo and Rania Tarazi, and extensive comments and advice from Mary Sue Smiaroski, Caroline Marrs, Carol Miller, Alivelu Ramisetty, Chloe Safier, Alex Pittman and Jeanette Kloosterman.

The paper is based on the Oxfam International Feminist Principles agreed at the Gender and Feminist MEAL Learning Event in Boston, USA, June 2013. 
The purpose of this practice paper is to share feminist principles for Oxfam's monitoring, evaluation, accountability and learning (MEAL) practice. Oxfam's commitment to women's rights, and to transforming unequal gender and power transformation, requires that we consider seriously how to track our contributions to these changes. Therefore, this paper provides reflections on the principles of feminist MEAL practice, as well as case studies of Oxfam program experiences in applying them.

Two dimensions are important to keep in mind in facilitating the application of these principles in MEAL systems:

- First, capturing changes in gender and power can be challenging methodologically and politically: while we would like to establish clear pathways from program activities to program results, it is often not so straight forward and simple. Yet there is often pressure (including from back-donors) to illustrate concrete results from program interventions. Further, many programs deal with complex issues where change takes a long time and does not always move forward as intended. Accounting for the reality of how change happens, including backlash where power was challenged, is important but not always fully understood or appreciated.

- Second, considering gender and power in our measurement practice requires Oxfam to examine whether we are consistent in practicing our own values. This entails providing space for program partners and participants to actively participate in MEAL design, being responsive to their capacity requirements and enabling them to challenge predefined processes and categories in order to design and implement MEAL systems that work for the kinds of change in gender relations they are working for.

We hope this paper will be useful for program and project officers, managers, program quality and MEAL staff working at country, regional and global levels. It may also be useful to staff of other agencies, and individuals curious about methods and lessons to support feminist MEAL practice.

\section{WHAT THIS PAPER IS - AND IS NOT}

The ideas and practices offered here represent a small step in a longer journey to strengthen Oxfam's collective understanding of feminist MEAL and what it means to put these principles into practice. It does not offer a template or toolbox for doing feminist MEAL: there is no one kind of feminism and there are many ways to monitor, evaluate and learn about the contributions of a program.

Instead, this paper offers examples and lessons learned that illustrate how aspects of the Oxfam International Feminist MEAL Principles ${ }^{1}$ have been used in the design and practice of MEAL systems. Specifically, this paper:

- Introduces the concept and challenges of gender transformational programming;

- Provides an overview of feminist principles as applied to MEAL;

- Presents case studies of these principles in practice;

- Discusses lessons for future consideration as other programs design and implement MEAL; and

- Shares resources for further consultation.

We know that we are only scratching the surface on an incredibly complex topic. The main hope is that this paper contributes positively to the knowledge base about how to do good MEAL that reflects Oxfam's commitment to gender justice and women's rights, while inspiring curiosity and courage among staff to give it a try. 


\section{THE COMPLEX NATURE OF TRANSFORMATIONAL CHANGE}

'Transformational change is long-lasting, systemic, sustainable change that challenges structures, culture and institutions that preserve inequality and injustice in the status quo.'

Oxfam Program Framework

Oxfam aims to contribute to transformational change..$^{2}$ supporting individuals and communities to challenge power, equitably and irreversibly, to realize their rights with dignity. ${ }^{3}$ This kind of change is complex. It is unpredictable and can happen in many different ways. It is also nonlinear. Often there are set-backs, backlash, and seemingly small steps forward, before major achievements are recognized.

One expression of Oxfam's commitment to transformation is our efforts to put women's rights at the heart of all we do. This commitment is core part of our rights-based approach to development and is underpinned by feminist thinking, which posits that gender inequalities lead to social injustice and that discrimination based on gender is structural and systemic.

Oxfam's approaches to supporting positive changes in gender inequality include work to change attitudes and beliefs, laws and policies, social norms and customs, and access to resources. We take multi-faceted approaches, knowing that changes in one of these domains are only sustainable with changes in another. For instance, legislation on violence against women can only be effectively implemented when a wide range of society and citizens reject the social norms that condone violence, and when adequate services are provided. Women's economic empowerment requires more than access to information and productive resources, it requires shifts in attitudes and beliefs about the worth of women's unpaid and paid work.

In relation to programs, this requires that:

- All programs and campaigns should be based on a gendered power analysis. ${ }^{4}$ All program and campaign design includes setting clear objectives and strategies likely to contribute to transformation of unequal gender and power inequalities.

- MEAL approaches must seek to reveal contributions Oxfam has made to change, and how these changes happened.

- MEAL systems and approaches should challenge existing power structures, enable us to learn from mistakes as well as achievements, challenge underlying assumptions and ask 'why' changes have occurred.

As part of Oxfam's accountability work, it would also be important to track to what extent our program investments and partnerships address these dimensions, over time. 
Building on the contributions of feminist monitoring and evaluation (M\&E) experts such as Srilatha Batliwala and Alex Pittman, the OI Feminist MEAL Principles are based on the understanding that discrimination based on gender identity is structural and systemic and that social justice in any context can be achieved only with change in power relations. Oxfam recognizes the autonomy and independence of partners in the work we do together, and is committed to relationships of mutual accountability. We recognize that evaluations and knowledge as political, transformative change processes are complex, and that change takes time and investment.

Thus, Oxfam MEAL should support the generation of knowledge that is meaningful, accessible and useful to those who rightly own it, and should:

\section{Planning}

- Examine gender and power relations, why they exist and how they change, and strive to produce knowledge in a way that acknowledges power;

- Be co-designed and co-managed with participants, so that participants agree on the assessment conclusions and how the evidence generated will be used;

\section{Tools}

- Use participatory tools and methods, encouraging broad participation, in particular by removing barriers to participation;

- Take a rights-based approach;

- Ensure that the process of measuring and evaluating impact and change is gender-just and rights-based;

\section{Self-awareness and attitudes}

- Acknowledge that persons facilitating evaluative processes should be self-aware and should possess skills including, but not limited to, facilitating, listening, interviewing, and writing/recording;

- Recognize that time is needed to build trust and understanding;

- Be flexible, adaptable and responsive to context, because originally proposed results and related indicators may be revised as people and organizations respond to change;

- Recognize that change is non-linear and complex, thus requiring the tracking and capturing of negative impacts, resistance, reaction, and unexpected outcomes;

- Use both qualitative and quantitative methodologies and methods that assess contribution, rather than demand attribution;

- Support strengthening of organizational capacity for meaningful engagement in feminist MEAL;

- Ensure that different levels of accountability are emphasized and seen as valuable by, for example, using meaningful feedback mechanisms; and

- Ensure that learning is incorporated and shared throughout the MEAL process and that it contributes to future work. 


\section{FEMINIST PRINCIPLES APPLIED TO OXFAM MEAL}

\section{The role of the evaluator and participatory approaches}

Putting feminist MEAL principles into practice depends to a large extent on whether the evaluator or the team leading the process ${ }^{5}$ is committed to feminist values and research ethics; recognizes MEAL as a political process; uses participatory processes that support reflection, capacity building and learning; and creates knowledge to be used by participants rather than to provide solutions. Applying such principles - especially around participation - to our MEAL approaches and practice is as important as their integration into the content and goals of a given program. ${ }^{6}$

As with programs themselves, MEAL happens in a social and political context and can be used (or misused) for personal and/or political ends. Staff and technical advisors supporting feminist MEAL should be willing and able to surface power relations, to consider how power shifts and why, to reflect on how their own positioning affects what they care about and what is measured, and to recognize that knowledge and values are shaped by cultural and social forces.

For instance, developing indicators for a monitoring system is not really an objective exercise. It requires evaluators and MEAL stakeholders to make choices and decisions that are inevitably shaped by the gender and power dynamics in a given context. While fixed indicators like 'numbers of women in a household' or predefined outcomes like 'increased women's access to land,' may be relevant and useful, feminist approaches facilitate space for local partners and men and women in the relevant communities to examine the meaning behind such ideas (i.e. what does 'access' mean?) and (re)define or add new indicators or outcomes as needed.

This process cannot be carried out in a bubble, however. A MEAL system can only be flexible and adaptive to the context if donors, program staff and dedicated technical support staff are equipped and empowered to adapt expected outcomes if needed and to capture the non-linear dynamics of change and course corrections.

Creating this type of process requires evaluators to be skilled at building confidence and trust so that marginalized voices will be heard throughout evaluation processes and within MEAL systems. Evaluators also need to fully understand the gender and power dynamics within a project or program and between participants in a specific process. Hiring an evaluator with the appropriate skills, knowledge and experience of feminist approaches to evaluation is important. Given that who you hire will make a difference in the MEAL results, we suggest the following criteria when hiring an evaluation consultant or officer:

\section{Concepts in 'feminist' vs. 'gender-sensitive' MEAL}

Gender sensitive monitoring and evaluation, in particular, is fairly widely accepted across development organizations as good practice. The focus is frequently on describing gender roles, responsibilities and relations; being as objective and neutral as possible;

disaggregating data by sex so that women's needs and interests can be taken into account throughout the program life-cycle; and being participatory.

Feminist MEAL methods draw on many of the same tools of gender -sensitive MEAL. Gender-sensitive MEAL can certainly be based on feminist principles and depends largely on who is leading or facilitating the MEAL.

Nevertheless, feminist MEAL explicitly challenges unequal power relations, and questions assumptions about gender identities and roles. A feminist approach to designing a MEAL system challenges the idea that MEAL concepts are neutral and the assumptions underlying predefined categories, including categories that make people's different gender identities, ages, ethnicities, religious, sexual orientations or wealth - or the intersection of all of these categories - invisible. A feminist approach recognizes that MEAL activities themselves can challenge or maintain power relationships. 
- Knowledge and experience implementing feminist and gender-sensitive approaches to evaluation;

- Strong expertise in qualitative and quantitative evaluation methods, and skills in facilitation, listening, and self-awareness;

- Commitment to ensuring that marginalized voices will be heard throughout evaluation processes and/or within MEAL systems.

Participants should agree how evidence will be analyzed and used. Learning should be incorporated throughout the whole process. Active engagement from Oxfam's partner organizations and other stakeholders should be pursued in the MEAL process, and their views should factor prominently in the creation of the MEAL approach, methods and tools.

Evaluators should try to make MEAL an empowering process that resonates with the interests and needs of the various stakeholders, including Oxfam staff, partners and community members, women and others who are often marginalized from decision making. In sum, evaluators can promote a participatory approach in line with feminist principles by ensuring that MEAL systems:

- Are co-designed with participants, with processes to collectively review and make sense of, and decisions about, evidence generated from the process;

- Are flexible, adaptable and responsive to context, because originally proposed results and related indicators may be revised as people and organizations respond to change;

- Use participatory tools and methods ${ }^{7}$ that explore gender and power relationships, encourage broad participation, in particular by removing barriers to participation, and favor collective and responsive learning;

- Build trust and understanding about how knowledge is used and is integral to a gender-just, rights-based approach to planning, MEAL and programming.

\section{Measurement for non-linear and complex change}

'One of the biggest challenges we have is to better capture the complexities of the development challenges we face in the field, in order to demonstrate the full impact of our efforts AND to better learn from our efforts so that the work that we take is truly transformational. I fear that much of the current push for a results agenda corners us into ignoring the nuanced and slow progress that we are able to achieve and undermines the validity of results that can't easily be counted.'

Oxfam staff member at 'Gender and Feminist Monitoring, Evaluation, Accountability and Learning' event

As with other forms of challenging social change, changes in gender relations are usually nonlinear and complex. What works in one context may have an entirely different effect in another. Change can also be unpredictable. A hypothesis of the results of an intervention is developed based on a good understanding of a context and community, but the exact outcomes can rarely be predicted. Further, changes that seem positive at first may erode over time. A hard won victory by community members for women's land rights can correlate with backlash against activists, or increases in violence against women. Such factors are common among social change processes. MEAL systems must help to track progress and achievements and capture negative impacts, resistance, reaction, holding ground and unexpected outcomes. ${ }^{8}$ Program plans and MEAL systems should also be flexible enough to adapt based on new information gathered.

The feminist MEAL principles do not prescribe one set of measurement tools or methods labelled 'feminist', nor do they place a preference on specific measurement tools or methods. They do stress that it is good practice to use complementary qualitative and quantitative methods to look at changes in gender relations. For instance, shifts in women's decision making 
authority, or men's attitudes about caring responsibilities, cannot be captured by numbers alone.

More importantly, the use of mixed methods over time enables the collection of different types of information and is vital in the process of triangulation of evidence of change.

In sum, measurement of non-linear and complex change, rooted in feminist principles, means:

- Tracking and capturing of negative impacts, resistance, reaction and unexpected outcomes;

- Using both qualitative and quantitative methodologies and methods that assess contribution, rather than demand attribution. 


\section{APPLYING FEMINIST MEAL PRINCIPLES: EXAMPLES FROM OXFAM AND PARTNER ORGANIZATIONS}

Most of the following examples are about stand-alone gender justice programs because these programs have most frequently made the strongest effort to consider gender and power relations throughout the work. We hope to see even more robust examples as Oxfam programs increasingly put women's rights at their heart.

\section{Why did we choose these examples?}

During the Gender and Feminist MEAL Learning Event in Boston in 2013, staff and partner organizations presented fascinating case studies on how they have challenged inequalities and influenced gender relations through appropriate MEAL systems. The following cases were chosen for this paper:

- Baseline design of the AMAL program. The program's baseline was done in a collective and participatory manner with the partners, women and men in communities where the program was implemented. They were flexible and adapted to the context, and used both qualitative and quantitative approaches.

- The Organizational Capacity Assessment Tool (CAT). ${ }^{9}$ The CAT was designed to work with organizations aiming to become stronger, gender-just organizations. It is an innovative self-assessment exercise that relies on partners to design their own context-specific capacity building strategies.

- An 'experiment' with Most Significant Change (MSC)..$^{10} \mathrm{MSC}$ is a participatory storytelling methodology that encourages learning processes whereby different stakeholders continuously exchange views and perspectives and decide on which change stories will be recorded. 


\section{AMAL: Supporting women's transformative leadership in changing times in the Middle East and North Africa by Oxfam Intermón}

Samia Khayyo and Rania Tarazi

\section{About the AMAL program}

AMAL is a three-year, multi-affiliate ${ }^{11}$ program, which promotes active participation and leadership of women with a focus on the poorest and most marginalized women in local, national and regional governance structures and decision making processes.

The program operates in Tunisia, Morocco, Occupied Palestinian Territories (OPT) and Yemen in partnership with 13 local organizations. The aims at country level are to develop capacity of women-led organizations, raise awareness of women's rights and participation and link women's activities to policy processes. All countries have the same outcomes and outputs, and use the same log frame and indicators. However, different approaches and activities are implemented in each country.
'What makes it a

[Transformative Leadership for Women's Rights] program is that all of our outcomes reinforce each other. We are not only working to build individual capacity of women, but their collective capacity, i.e., women, organizing themselves, identifying issues that impact their communities, and addressing those issues which they can address too.'

AMAL Program Manager

In Morocco: community mobilization to ensure the 2011 constitution and elections laws promoted gender equity in all spheres of life; capacity building of women on the articles of the constitution that support gender equality; supporting women to identify what gender equality means to them; capacity building of women political candidates, to help strengthen their ability to represent their communities.

In Tunisia and OPT: awareness raising focused on youth in marginalized areas, targeting young women and men on various topics including social and economic rights; establishing networks between youth and older generations of leaders; training political leaders/candidates and leaders in CSOs; providing infrastructure and access to basic services for women in poor and marginalized areas; capacity building for women to campaign in Tunisia; and pushing for a 30 percent quota for women in political parties in OPT.

In Yemen: literacy training using the REFLECT methodology to identify community issues and enable participants to become members in local community committees, raise community issues and identify solutions with local authorities. Additionally at higher levels, for instance at national level, the program helps women to raise issues that cannot be addressed locally. However, the situation is fragile and future plans are uncertain.

New local-level research is currently carried out across the region to identify barriers that women face to formal and informal leadership, with a focus on poor areas. The research will also identify strategies used by women themselves to change their situations. The purpose of the research is to change the perceptions that poor women do not have knowledge and are not leaders. This is part of a regional campaign that aims to change perceptions about women's roles and leadership and to increase investment in women's participation, especially at local levels. Apart from this, the regional component includes capacity building on advocacy and media for partner organizations.

At the global level, the program aims to share learning more widely and advocate for government and donor policies that preserve and advance women's rights in the region.

MEAL example: Developing (and supporting) a participatory baseline methodology

A MEAL system was agreed upon based on Oxfam offices, partners' expertise, capacity and budget, with the MEAL system defining roles for Oxfam staff and partners. The plan took into 
consideration the baseline experience of partners, enabling them to build on their strengths focus groups and interviews - while other methods were implemented by an independent consultant. In some countries, the partners did not want to do baseline research as proposed, and in these cases a consultant was hired to do the whole baseline. Partners were introduced to new, less labor-intensive tools that have helped them with the AMAL program as well as other work. Training was provided by country offices where possible, and where MEAL officers were present; otherwise it was provided by regional staff and external experts.

\section{Feedback on the implementation of the tool from Oxfam and partner staff}

'All participants feel that they have learn[ed] from the exercise, like knowing more about [Women's Transformative Leadership] and the reality of Oxfam's status and the gaps. In terms of feedback, the process of the exercise was suitable and allowed them to think deeply.'

'The positive thing they have noticed in the exercise is that it is a good opportunity for sharing and learning...' Participant in program workshop
As per the agreed MEAL system, all countries were meant to set a MEAL committee from the beginning to harmonize the work and monitor implementation of the MEAL plan. However, with the exception of Morocco, most countries did not do this due to capacity and time constraints. Instead, MEAL monitoring functions were incorporated into existing management structures to avoid burdensome additional requirements.

During the design phase, with technical support from Oxfam regional staff, a single log-frame was developed for the four participating countries. Where necessary, countries added context-specific indicators.

In sum, feminist MEAL principles shaped the design phase of the study as follows.

- A review of the program logical framework was carried out to ensure that the intervention followed a clear and consistent logic and that the overall objective, project purpose, outputs and activities built on one another and reflected the theory of change.

- A brief assessment of country offices' and partners' MEAL capacity was made with a harmonized capacity assessment tool that asked, for instance, about their training and experience in monitoring, evaluation and learning. This process gave colleagues information about capacity development needs.

- A baseline was carried out, using tools developed according to the rights-based approach and the principles of Women's Transformative Leadership (WTL). ${ }^{12}$ This included focus groups, an adapted transparency and participation tool and an opinion formers' survey to measure attitudes, capacity and commitment to the women's transformative leadership tool presented below. The aim of combining these methods was to produce results that would properly reflect the complexity of processes and situations in the most accurate way possible.

- The MEAL system - agreed upon data collection and analysis methods - included the definition of indicators in the log frame, revised previously established targets, and set the starting point for outcome and output indicators against which performance was to be monitored.

\section{Challenges}

Building ownership among the partners on MEAL was not easy. Buy-in needed to be established from the very start, while we developed the program. In this case, the partner was resistant because they were not expecting baseline research. We need to change the culture of program development so thinking about our activities and how we will monitor them is a joint process that needs to be agreed on (and sometimes negotiated) together with partners. 
One challenge with the baseline was that some MEAL components were more defined than program work plans as the latter were developed in good time with partners. Therefore there was a need to align the timing of the baseline to the timing of program implementation. As a result, it was not feasible to do the whole baseline at the beginning for all indicators. Instead, the baseline was phased according to program plans.

In practice, the process was participatory, with Oxfam staff and partner organizations developing a learning-oriented partnership, contributing to the capacity building and learning processes of the program. For instance, many times tools were developed (and often adapted to each country context) during capacity building and learning processes, and based on change processes partners wanted to measure. Partners increasingly took ownership of MEAL processes, despite the challenges. Learning was also generated through focus group discussions with women participants that used guiding questions on the indicators measured in the baseline.

\section{The Women's Transformative Leadership Tool}

This tool was developed based on the concepts outlined in Feminist Leadership for Social Transformation ${ }^{13}$ to support organizations and movements to broaden, deepen and democratize their leadership base. The AMAL program used it to assess existing organizational skills and knowledge in five dimensions of women's leadership: power, principles/values, politics/purpose, practices and the self.

Oxfam also monitored its own practice, based on the indicator '\% of Oxfam offices and partner organizations that show improvement in knowledge, skills and tools on transformative leadership by the end of the project (compared with baseline)'. This was measured in plenary discussions with partner staff members at different levels in the hierarchy, which allowed participants to learn more about women's transformative leadership and to identify gaps in their organizational practices. Areas of improvement identified during the implementation of the tool were used to design activities that tackle WTL practices in partner and Oxfam offices.

A set of criteria was also designed for each of the four dimensions of leadership, enabling organizations to self-assess and reflect on their own leadership practices, knowledge and skills and to identify gaps and areas for improvement. All of this contributed to the empowerment and to the learning process of the organizations.

\section{Lessons learned}

- Having a plan and providing funds for training on M\&E is critical. Resources are needed to convene partners and Oxfam staff, to communicate and create MEAL systems face to face, and to build capacity where needed. In this case, a 4-5 day training at the outset would have been very useful.

- In retrospect, the MEAL system could have been developed together with the baseline, to simplify the process. MEAL processes can be difficult to sequence, particularly under pressure of funding and spending requirements. It is recommended to dedicate a period of inception where the MEAL system would be developed before activities start.

- The principles and values of feminist transformative leadership should be integrated at the beginning of the process to define the approach of the baseline study. The guiding principles were revisited at each step to make sure that the baseline study was in accordance with them.

- The individuals/team developing the MEAL system need to share the values and principles of feminist leadership to be able to reflect those principles in practice. 
- We should not take for granted that everyone will use a feminist lens. Although the tools enhance and promote the inclusion of peers, participation, learning and empowerment, the facilitators who use the tools must also be determined and able to apply them in practice. In some cases, this may require an additional effort to explain the value that applying these principles adds to the quality of the process and the results of the baseline. There is a need to emphasize constantly that the process itself and how we implement the tools is as important as the results themselves.

- In addition to country MEAL committees, given the regional nature of the work, a regional committee could have also been helpful, to mark when milestones related to the MEAL plan are met and to ensure the work is properly resourced.

\title{
2 Bringing feminist principles to the assessment of organizational capacity for gender justice: Oxfam Canada's Engendering Change program
}

\author{
Carol Miller
}

\section{About the Engendering Change program}

Engendering Change (EC) was a stand-alone women's rights and gender equality program implemented by Oxfam Canada between 2009 and 2014. The program consisted of a portfolio of 44 partner organizations of different sizes, budgets, and missions, working in regions and countries as diverse as Central America and Cuba, the Horn and East Africa, southern Africa, and Asia. Partners included women's and feminist organizations and networks, as well as mixed NGOs, membership organizations, and co-operatives. The EC program provided partners with organizational capacity building to support their paths to becoming stronger, gender-just organizations. Organizational capacity building support included, for example, promoting transformative women's leadership, encouraging dialogue on gender issues, supporting gender budgeting, development of sexual harassment policies, interventions to support work-life balance as well as programmatic gender mainstreaming support.

The program also provided funding to partners for both core expenses and programs which varied according to community-identified needs in themes such as women's leadership, women's economic empowerment, and elimination of gender-based violence.

\section{MEAL example: The organizational Capacity Assessment Tool (CAT)}

Oxfam Canada (OCA) and partners wanted to be able to track and assess their progress in becoming gender-just organizations. To this end, they grappled with a number of questions: How would Oxfam Canada know transformative organizational change if they saw it? Would changes look different within different types of partner organizations and from the perspectives of different stakeholders?

Thus the first step was to realize that the program needed a MEAL system - a system that integrated multiple and diverse methods at different points in time, as a way to better capture the reality of complex change both within partner organizations themselves and, of course, across the program overall. The evaluation of the EC program is based on a developmental evaluation approach and the use of mixed methods. ${ }^{14}$

To illustrate further the challenges and practicalities of practicing feminist MEAL, we focus here on the program's organizational capacity assessment and benchmarking tool, known as 'the CAT' by Oxfam staff and partners. ${ }^{15}$ 


\section{The Capacity Assessment Tool (CAT)}

The CAT was designed as a participatory self-assessment exercise around which EC partners could identify needs and design a context-specific capacity building strategy to support them in becoming stronger, gender-just organizations. Some components of the strategy were then funded by the EC program, but the strategy itself was owned by partners and could be used as input into their capacity development strategies. In line with Oxfam's partnership - and feminist principles - it was important that the CAT process engaged partners in self-reflection and assessment, rather than having had their capacity assessed by outside evaluators. ${ }^{16}$ The CAT approach honors the experience and perspectives that participants bring to the exercise, and engages them in a conversation about current organizational capacities compared with their perceptions of the capacities needed to undertake effective gender-just work.

The CAT assessment framework is designed to be sufficiently flexible to accommodate the diverse starting points and unique pathways of each partner. That said, it also generates a specific numerical rating in a variety of capacity areas, which allows Oxfam Canada to aggregate information that helps compare and contrast annually, allowing trends to emerge by region and partner types. For example, the CAT surfaces common challenges, such as limited knowledge in organization-wide monitoring and evaluation systems faced by women's and feminist organizations throughout the three regions of the program.

Program partners conducted an annual self-assessment based on the CAT. While the exercise was a valuable tool for program monitoring by OCA, partners themselves found the 'selfmonitoring' process equally valuable. During the EC program, the CAT self-assessment scores were revisited and reflected on by partners and Oxfam each year. Feedback from partners suggests that intentionally revisiting and reassessing capacity to work on particular issues, and linking this to an analysis of gender power relations in their own organizations allowed each partner the opportunity to 'own' the self-assessment process. From that point, they could have an honest conversation about progress as well as set-backs and reversals in their organizational capacities, for example, the impact of turnover of staff with gender expertise, or changes in leadership. As noted by one CAT participant: 'The capacity building exercise is extremely useful...it helps us to track progress and identify capacity gaps on our own., ${ }^{17}$

\section{Lessons learned}

\section{Getting the process right:}

- Taking a feminist approach to MEAL requires soliciting and honouring the perspectives and knowledge of partners as evidence of how capacity building programmes are experienced. This logically leads to the use of participatory MEAL tools and methods.

- Feminist-inspired MEAL processes require considerable time investment and work best with partners who are committed to experimenting with such processes.

\section{Respecting diversity, context and complexity:}

- The CAT created space for diverse partners to identify where they were on their pathways to becoming gender-just organizations, and required us to acknowledge that what transformative change looks like can be context- and partner-specific.

- The CAT processes opened up spaces that captured the non-linear nature of organizational change experienced by partners; while it was a positive step in putting feminist principles into practice, it presented challenges when it came to reporting against pre-determined outcomes laid out in the EC program performance measurement framework.

\section{Shifting the power in MEAL:}

- Upward accountability reporting (reporting to donors) can be burdensome for partners; this can be mitigated by designing MEAL processes that are useful and relevant for multiple stakeholders. 
- Wherever possible, we attempted to use evaluative processes that helped to shift power relationships from partners having monitoring and evaluation conducted 'on' them to partners being more in control of evaluative processes. This was at times quite challenging as it required being open to having the process unfold differently than anticipated.

\title{
3 Oxfam Novib's implementation of 'Most Significant Change' in the context of Gender Mainstreaming and Leadership Trajectory (GMLT)
}

\author{
Jeanette Kloosterman
}

\begin{abstract}
About the Gender Mainstreaming and Leadership Trajectory
Oxfam Novib's Gender Mainstreaming and Leadership Trajectory (GMLT) was formally launched in 2008 as a three-year action learning trajectory aimed at creating evidence-based changes towards greater gender justice sensitivity and practice in Oxfam Novib's partner organizations, in their programs and communities where they work. ${ }^{18}$ GMLT strives to foster tangible changes (like the formulation of gender policies) as well as intangible changes in deeply held cultural norms and exclusionary practices, reflected in the beliefs, behaviors and attitudes of people, organizations and institutions.
\end{abstract}

\section{MEAL example: Most Significant Change (MSC) ${ }^{19}$}

While GMLT had no difficulties assessing quantifiable results, for example, the number of women in senior positions in an organization or the number of organizations that have a gender justice policy in place, it was challenging to collect information that makes qualitative change visible. Until recently the MEAL tools at hand were not able to capture that kind of change.

The MSC methodology was selected as an appropriate complementary qualitative approach for collecting evidence of behavioral and attitudinal changes regarding gender equality. The Measuring Milestones Initiative was designed as a collaborative initiative between Oxfam Novib, Gender@Work and program partners to gain knowledge and expertise on the usefulness of adding MSC to the existing GMLT monitoring and evaluation tools.

To kick-off the experiment with MSC in 2010, 20 partner organizations and 12 gender consultants from 12 different countries were trained in the methodology and applied it in the following years. The use of MSC fit well with the feminist MEAL principles given that:

- It is based on stories, a qualitative approach that surfaces participants' own views;

- It involves different stakeholders in a participatory fashion in deciding what changes to record and analyze;

- It facilitates learning because participants continuously exchange views and perspectives among each other, and learn from each other's experiences.

MSC is carried out throughout the program cycle and provides information to help people manage the program; it contributes to evaluation by providing data on outcomes and impact that can be used to help assess the performance of the program as a whole.

Core components of this approach are the collection of stories of change that emanate from the communities where the development initiative is taking place, and the systematic selection of the most significant of these stories by panels of designated stakeholders or staff. As soon as the stories have been collected, the panelists meet, sit down together, read the stories aloud and have regular and often in-depth discussions about the value of these reported changes and impacts. 
The full methodology contains 10 implementation steps:

1. Starting and raising interest

2. Defining domains of change

3. Defining the reporting period

4. Collecting significant change stories

5. Selecting the most significant change stories

6. Feeding back the results of the selection process

7. Verifying the stories

8. Quantification

9. Secondary analysis and meta-monitoring

10. Revising the system

As a monitoring and evaluation methodology, MSC is best suited to focus on mutual learning rather than just accountability. For example, a story collector learned about new initiatives at field level when she interviewed a teacher who had once attended one of her organization's training sessions. Inspired by the training, the teacher started a girl's football team. The story collector had never heard about this initiative before and started to think about how their organization could inspire similar initiatives. ${ }^{20} \mathrm{MSC}$ can be a powerful method for capturing rich descriptions of the qualitative changes in people's attitudes, beliefs and behavior.

\section{Lessons learned}

- Storytelling can be an important strategy to create a renewed energy to share, debate and embrace the complexity of changing gender power relations because it makes change processes easier to grasp.

- 'Hearing and discussing change stories has made me aware that I also play a role in the process of gender mainstreaming. The stories show real change and I play a role in these changes. I tend to think about gender mainstreaming as something outside myself.... Now I realize that I am part of very inspiring changes.' ${ }^{21}$

- It was a challenge to attribute observed qualitative changes to the intervention, but helped Oxfam and partners to gain clarity on what changes realistically linked to the intervention and how the changes happened.

- It is important that participants have good analytical skills, as this influences the selection of stories and how well they are understood. Active-listening skills are critical as well, as is the relationship between the storyteller and the story collector. All of this influences the outcome of the story.

- Building trust is really important with MSC, because if the story collector does not value the story of the story teller, this can damage relationships and the quality of the story overall. This underscores the need to allocate sufficient time to engage in MSC methodologies.

- Mind-sets must be shifted from seeing change as particular achievement, to understanding the process that led to the achievement as just as important.

- MSC can be a resource and time consuming exercise, and whether or not this method is feasible and desirable needs to be considered at the outset: 'The method is very interesting and the sacrifices made to use it have been worth it, but I am still eager to know how to overcome the administrative heaviness and how to overcome unwillingness and lack of resources to use this methodology. 22 


\section{NEXT STEPS AND RECOMMENDATIONS}

\section{Feminist principles and log-frame approaches}

In the case studies presented, participatory, qualitative MEAL approaches were stressed because they are so central to surfacing, understanding and challenging gender inequality. But as in the CAT example shown above, qualitative methods can be used to complement quantitative data, for instance by helping us to understand emerging trends.

The feminist principles also stress that the process of developing MEAL systems is crucial. For this reason, Oxfam believes that more linear methods like log-frame approaches ${ }^{23}$ are compatible with a feminist MEAL perspective if they are developed and implemented in a flexible manner that allows gender and power relations to be explored and which integrates a participatory process. As the AMAL example shows, Oxfam adapted the global log-frame together with partners in the region as part of a monitoring system that provided many opportunities for local partner organizations to influence and change the initial planning.

\section{Creating reflective spaces for Oxfam, partners and other stakeholders}

These case studies illustrate an important role for Oxfam: as a facilitator of processes of reflection and learning from credible evidence, from a variety of sources and perspectives, rather than imposing ourselves as 'experts' (even where we provide technical support). This way of working allows stakeholders to reflect, analyze and take collective action on a project's approach. As already stated, developing MEAL systems in line with a feminist perspective requires valuing and promoting the perspectives and knowledge of local partners and women and men as stakeholders in development.

If we want to include a focus on power relations in how we engage with our grantees around MEAL, then we need to create opportunities for reflection for all relevant stakeholders: program staff, partners and community members. Throughout a program's tenure, stakeholders need time to reflect together on power and how it can be transformed, and on changes in the social and political context. This is just as important for an accountability mechanism that includes clear responsibilities and good relationships between all stakeholders involved as it is for the monitoring, evaluation and learning aspects of a MEAL system.

'When you work for women's interests, it's two steps forward - and at least one step back. And those steps back are...often evidence of your effectiveness; they represent the threat you have posed to the power structure, and its attempt to push you back. ${ }^{24}$

Srilatha Batliwala and Alex Pittman. Capturing Change in Women's Realities.

\section{Allocation of time and resources}

All three examples showed that feminist MEAL requires time and resources, sometimes above and beyond the standard allocations for MEAL. Transformational change looks different from region to region, and from program to program. Time and investment is needed to ensure partners can experiment with the system, processes and methods that will work best in a given context. For instance, as the example of Oxfam Canada's CAT demonstrates, honouring context and partner diversity should be balanced with the need to aggregate data to create a narrative about a program, or to track important trends that transcend context specificity, such as current challenges faced globally by women's and feminist organizations. 
Oxfam works in a wide range of contexts, but also has a set of common change goals and objectives it is working towards, as well as strategies and activities to achieve them. Even as we honor context and partner diversity, we need to allow for the possibility of comparing data across settings and encouraging cross-site learning where appropriate, or creating a programmatic narrative.

\section{Limits of our MEAL systems: capturing qualitative change}

Last but not least, we need to be realistic about the extent to which our MEAL systems can articulate our contribution to transformational change and the elimination of gender inequalities. The kinds of changes we are working towards - in attitudes and norms about gender - take years, often a full generation, to happen. That is well beyond the timeframe of any program, so our MEAL systems must in some way reflect this reality. In a complex world with many interacting stakeholders, programs and interventions, the challenges of monitoring, evaluating and learning from complex transformational change are significant, so a thoughtful MEAL response is more necessary than ever.

\section{Be open to surprises and experiment with new methodologies}

Given Oxfam's commitment to working together with our partners and with the women and men in the communities where we work, staff must be prepared to challenge our own assumptions about how change happens, so that our programs can be vibrant spaces for learning and results. We should be willing to share our experiences and learn from others (from within Oxfam, our partners, and certainly beyond). We should consider how other methods, such as outcome mapping, action research, feedback loop mapping and circular dialogues can be further explored for incorporation in Oxfam's long-term development programs and campaigns. ${ }^{25}$ These methods offer exciting opportunities to change complex patterns of power and to operate on the basis of non-linearity and unpredictability.

\section{Link analysis, planning, monitoring, evaluation and learning}

If we want to challenge existing power relations and gender inequalities we need to continue to link analysis, planning, monitoring and evaluation more closely to each other. The examples described above all made a deliberate effort to be coherent in this respect. Within Oxfam this linkage can often be improved so that our context analysis is more closely reflected in the planning phase of a program and MEAL is integrated into the whole program.

\section{Further elaborate on how the feminist planning and MEAL principles can be applied in Oxfam's campaigns and humanitarian assistance}

Given Oxfam's commitment to human rights and gender justice, the creation of MEAL systems based on the feminist principles is ultimately just good MEAL. The focus of this paper has been on long-term development, as this is where the bulk of our experimentation and application of feminist MEAL principles has played out up to this point. However, subsequent reflections will add to our collective knowledge on good practice - for instance, how the principles can apply specifically to our humanitarian and campaigning work, and the specific 'how to's' of feminist MEAL. 


\section{Oxfam Gender and Feminist Monitoring, Evaluation, Accountability and Learning event}

\section{ARTICULATION OF FEMINIST PRINCIPLES}

\section{Introduction}

Theories and practice characterized most discussions at the gathering of partners, experts and Oxfam staff on Gender and Feminist Monitoring, Evaluation, Accountability and Learning (MEAL) held in Boston on June 4-6, 2013. The learning event included representation from 11 Oxfam affiliates, and included a diversity of approaches and perspectives from countries and regions. Over the course of three days, the group shifted from speaking of 'feminist evaluation' in favour of referencing 'feminist principles to guide MEAL practice' ${ }^{26}$ In a number of sessions, various principles were presented, debated, and discussed. The group agreed it would be helpful for the confederation if the group could pull together a common articulation of feminist principles to guide MEAL - both for the group's learning and as input to a number of program quality and MEAL processes currently underway in the confederation.

The present paper presents a list of principles, gathered from the presentations and discussions in Boston. Event participants were asked to provide input with the goal of agreeing a final set of principles that will contribute to guidance on MEAL work and approaches that Oxfam takes forward. We agreed that the statement should be a living document that is written in accessible language.

\section{Feminist principles to guide MEAL in Oxfam}

\section{Because}

- Oxfam seeks the transformation of unequal gender and power relations because inequality leads to social injustice generally and discrimination against and disempowerment of women specifically,

And since:

- Discrimination based on gender identity is structural and systemic, and

\section{Because:}

- Oxfam recognizes the autonomy and independence of partners in the work we do together, and is committed to a relationship of mutual accountability, while at the same time recognizing that power imbalances may exist between Oxfam and its partners,

And since:

- A transformative approach recognizes all contributions, no matter how small they seem, as steps in changing gender and power relations, and the necessity of women to have meaningful participation and set their own agendas in all decision making processes,

\section{And recognizing:}

- That any kind of assessment, like evaluation, has a political dimension, because conclusions about effectiveness or relevance are often used to make decisions about the continuation, or not, of programs;

- That knowledge and values are shaped by cultural and social forces that are specific to particular times; 
- That transformative change processes are complex - they are not linear and often include periods of apparent regression or stasis; ${ }^{27}$

- That change, and understanding change, take time and investment;

- That assessment processes, like programs themselves, do not occur in a vacuum and, as such, need to take into account both organizational capacity issues and gendered barriers to participation; and

- That learning is both what happens during the process, as well as what is done with the information collected.

Oxfam MEAL should support the generation of knowledge that is meaningful, accessible and useful to those who rightly own it, and therefore should:

- Examine gender and power relations, why they exist and how they change, and strive to produce knowledge in a way that acknowledges power;

- Be co-designed and co-managed with participants, including agreement on the assessment conclusions and the use of evidence generated;

- Ensure that the process of measuring and evaluating impact and change be gender-just and rights-based;

- Use participatory tools and methods, encouraging broad participation, in particular by removing barriers to participation;

- Acknowledge that persons facilitating evaluative processes should be self-aware and should possess skills including, but not limited to, facilitation, listening, interviewing, and writing/recording;

- Recognize that time is needed to build trust and understanding;

- Be flexible, adaptable and responsive to context because originally proposed results and related indicators may be revised as people and organizations respond to change;

- Recognize that change is non-linear and complex, thus requiring the tracking and capturing of negative impacts, resistance, reaction, and unexpected outcomes;

- Use both qualitative and quantitative methodologies and methods that assess contribution, rather than demand attribution;

- Support strengthening of organizational capacity for meaningful engagement in feminist MEAL;

- Ensure that different levels of accountability are emphasized and seen as valuable by, for example, using meaningful feedback mechanisms; and

- Ensure that learning is incorporated and shared throughout the MEAL process and contributes to future work.

June 2013 


\section{BIBLIOGRAPHY}

Batliwala, Srilatha (2011). Feminist Leadership for Social Transformation: Clearing the Conceptual Could. CREA.

Batliwala, Srilatha and Pittman, Alexandra (2010). Capturing Change in Women's Realities: A Critical Overview of Current Monitoring and Evaluation Frameworks and Approaches. AWID, December.

Benning, Esther, Jeanette Kloosterman and Rex Fyles (2012). Learning About Gender Equality, Oxfam Novib, July.

Burns, Danny (2007). Systemic Action Research: A Strategy for Whole System Change. The Policy Press, University of Bristol, October.

Davis, Rick and Jess Dart (2005). The 'Most Significant Change' (MSC) Technique: A Guide to Its Use, April.

Earl, Sarah, Fred Carden and Terry Smutylo (2001) Outcome Mapping. Building Learning and reflection in Development Programs. International Development Research Centre, Ottawa. www.outcomemapping.ca

Khayyo, Samia. (2013) AMAL: Supporting Women's Transformative Leadership in Changing Times in Middle East and North Africa: Baseline Methodology Design. Internal document, Oxfam GB, March.

Kloosterman, Jeanette (2014). Transformative Leadership for Women's Rights - An Oxfam Guide, May.

Köerppen Daniela, Norbert Ropers and Hans J. Giessmann (2011). The Non-Linearity of Peace Processes - Theory and Practice of Systemic Conflict Transformation. Barbara Budrich Publishers, August. Budrich Verlag, August.

Miller, Carol and Laura Haylock (2014). Capturing Changes in Women's Lives: The Experiences of Oxfam Canada in Applying Feminist Evaluation Principles to Monitoring and Evaluation. Gender and Development Journal, Vol 22, No 2, July.

Oxfam Canada (2012). The Power of Gender Just Organizations. Oxfam Canada.

Patton, Michael Quinn (2010). Developmental Evaluation: Applying Complexity Concepts to Enhance Innovation and Use, Guildford Press, London.

Pittman, Alexandra (2014). Fast-Forwarding Gender Equality and Women's Empowerment?: Reflections on Measuring Change for UNDP's Thematic Evaluation on Gender Mainstreaming and Gender Equality 2008-2013, Independent Evaluation Office, UNDP.

Podems, Donna (2010). Feminist Evaluation and Gender Approaches: Is there a difference? Journal of Multi-Disciplinary Evaluation, Volume 6, No 14, August 
1 See Annex 1 for the full set of Oxfam Feminist MEAL Principles agreed in Boston, June 2013 during the 'Gender and Feminist Monitoring, Evaluation, Accountability and Learning' event organized jointly by the Oxfam Gender Justice Team and the Oxfam Affiliate MEL Colleagues Network. This gathering of practical visionaries was characterized by deep passion and thoughtful reflection on how to measure changes in gender and power relations.

2 The concepts and process of transformational programming are elaborated in several Oxfam documents, including Transformative Leadership for Women's Rights - An Oxfam Guide, May 2014. www.oxfam.org/en/policy/transformative-leadership-women-rights-oxfam-guide and Ending VAW: An Oxfam Guide, November 2012. https://www.oxfam.org/en/research/ending-violence-against-women (accessed May 2016)

3 Oxfam Program Framework.

4 Gendered power analysis should be conducted at the beginning of every new program (see, for instance, Oxfam Program Standards

https://www.oxfam.org/sites/www.oxfam.org/files/file_attachments/story/oxfam-programstandards_1.pdf (accessed May 2016)

5 Ibid.

6 Ibid.

7 For additional descriptions of alternative ways to measure gender equality, women's rights and women's empowerment see http://web.undp.org/evaluation/documents/articlespapers/occasional_papers/Occasional\%20Paper_Gender_Pittman\%20.pdf (accessed May 2016)

8 S. Batliwala and A. Pittman (2010). Capturing Change in Women's Realities: A Critical Overview of Current Monitoring and Evaluation Frameworks and Approaches. AWID, December 2010. See http://brookeackerly.org/wp-content/uploads/2010/11/Batliwala-2010.pdf (accessed May 2016)

9 See The Power of Gender-Just Organizations: Toolkit for transformative organizational capacity building. http://www.oxfam.ca/sites/default/files/Ox-Gender-Toolkit_web-final_0.pdf for a full description of the tool. (accessed May 2016)

10 See http://genderatwork.org/Portals/0/Uploads/Documents/Resources/Learning-about-GenderEquality.pdf for more information. (accessed May 2016)

11 AMAL means hope in Arabic. Oxfam affiliates Oxfam GB, Oxfam Intermon and Oxfam Novib are responsible for managing and delivering the program that started in 2011.

12 See Transformative Leadership for Women's Rights: An Oxfam Guide. http://www.oxfam.org/en/policy/transformative-leadership-womens-rights-oxfam-guide (accessed May 2016)

13 S. Batliwala (2011). Feminist Leadership for Social Transformation: Clearing the Conceptual Cloud. http://www.creaworld.org/sites/default/files/Feminist\%20Leadership\%20For\%20Social\%20Transformat on_0.pdf (accessed May 2016)

14 Developmental evaluation is an evaluation approach that can assist social innovators to develop social change initiatives in complex or uncertain environments. For a more in-depth description, see M.Q. Patton (2010). Developmental Evaluation. Applying Complexity Concepts to Enhance Innovation and Use. London: Guildford Press.

15 The CAT assessment framework and suite of tools are available at: http://www.oxfam.ca/sites/default/files/Ox-Gender-Toolkit_web-final_0.pdf. (accessed May 2016)

16 Some perspectives held that partner self-assessment would not be accurate or credible, for a variety of reasons, and favored instead the idea of using external evaluators to periodically assess partner capacity. This was rejected for a number of key reasons: a) OCA's research confirmed that there are no 'objective' standards of what ideal capacity looks like in an organization; b) OCA's analysis of and experience with partner-led development showed that, as a general rule, partner organizations had a strong interest in accurately assessing their own capacity; c) the act of assessment is a political one and the program was committed to demonstrating its understanding of that concept. In addition, and in related fashion, the program's MEAL approach rejected the idea that partner organizations needed to demonstrate steady 'progress' in the form of increasing ratings over the life of the program.

17 https://oxfam.ca/sites/default/files/imce/partner_survey_oxfam_english_2011.pdf (accessed May 2016)

18 See also Oxfam Novib (2012). Learning about Gender Equality. July 2012. http://www.genderatwork.org/Portals/0/Uploads/Documents/Our-Approach/Learning-about-GenderEquality.pdf (accessed May 2016).

19 MSC is tool to help clarify the results from a project, program or activity from beginning to beyond the period of funding. It was developed by IDRC, and has been widely used since the late 1990s by development, human rights and social services organizations.

20 Oxfam Novib (2012). Op. cit. p. 17. 
21 Quote from an Oxfam Novib partner organization in Bangladesh, cited in Oxfam Novib (2012). Op. cit. p. 22.

22 Oxfam Novib (2012). Op. cit. p. 26.

23 For further information on log-frame approaches, see http://betterevaluation.org/evaluationoptions/logframe (accessed May 2016)

24 S. Batliwala and A. Pittman (2010). Capturing Change in Women's Realities: A Critical Overview of Current Monitoring and Evaluation Frameworks and Approaches. AWID, December 2010. http://www.awid.org/sites/default/files/atoms/files/capturing_change_in_womens_realities.pdf (accessed May 2016)

25 See for example: Danny Burns (2007). Systemic Action Research. The Policy Press; Körppen and Ropers (2011). The Non-Linearity of Peace Processes - Theory and Practice of Systemic Conflict Transformation. Budrich Verlag.

26 During the event, a number of participants advocated for the inclusion of design as well.

27 For example, women's rights programs and the organization promoting them can experience backlash, which may actually be a sign of success in the road of transforming gender and power relations. 


\section{Oxfam Discussion Papers}

Oxfam Discussion Papers are written to contribute to public debate and to invite feedback on development and humanitarian policy issues. They are 'work in progress' documents, and do not necessarily constitute final publications or reflect Oxfam policy positions. The views and recommendations expressed are those of the author and not necessarily those of Oxfam.

For more information, or to comment on this paper, email kim.henderson@oxfaminternational.org or marysue.smiaroski@oxfaminternational.org

(C) Oxfam International July 2017

This publication is copyright but the text may be used free of charge for the purposes of advocacy, campaigning, education, and research, provided that the source is acknowledged in full. The copyright holder requests that all such use be registered with them for impact assessment purposes. For copying in any other circumstances, or for re-use in other publications, or for translation or adaptation, permission must be secured and a fee may be charged. E-mail policyandpractice@oxfam.org.uk.

The information in this publication is correct at the time of going to press.

Published by Oxfam GB for Oxfam International under ISBN 978-0-85598-996-5 in July 2017.

Oxfam GB, Oxfam House, John Smith Drive, Cowley, Oxford, OX4 2JY, UK.

\section{OXFAM}

Oxfam is an international confederation of 20 organizations networked together in more than 90 countries, as part of a global movement for change, to build a future free from the injustice of poverty. Please write to any of the agencies for further information, or visit www.oxfam.org.

Oxfam America (www.oxfamamerica.org)

Oxfam Australia (www.oxfam.org.au)

Oxfam-in-Belgium (www.oxfamsol.be)

Oxfam Brasil (www.oxfam.org.br)

Oxfam Canada (www.oxfam.ca)

Oxfam France (www.oxfamfrance.org)

Oxfam Germany (www.oxfam.de)

Oxfam GB (www.oxfam.org.uk)

Oxfam Hong Kong (www.oxfam.org.hk)

Oxfam IBIS (Denmark) (www.ibis-global.org)
Oxfam India (www.oxfamindia.org)

Oxfam Intermón (Spain) (www.oxfamintermon.org)

Oxfam Ireland (www.oxfamireland.org)

Oxfam Italy (www.oxfamitalia.org)

Oxfam Japan (www.oxfam.jp)

Oxfam Mexico (www.oxfammexico.org)

Oxfam New Zealand (www.oxfam.org.nz)

Oxfam Novib (Netherlands) (www.oxfamnovib.nl)

Oxfam Québec (www.oxfam.qc.ca)

Oxfam South Africa (www.oxfam.org.za) 